\title{
Age heterogeneity of soil organic matter
}

\author{
J. Rethemeyer ${ }^{\mathrm{a}, *}$, P.M. Grootes ${ }^{\mathrm{a}}$, F. Bruhn ${ }^{\mathrm{a}, \mathrm{b}}$, N. Andersen ${ }^{\mathrm{a}}$, \\ M.J. Nadeau ${ }^{\text {a }}$, C. Kramer ${ }^{\mathrm{c}}$, G. Gleixner ${ }^{\mathrm{c}}$ \\ ${ }^{a}$ Leibniz-Labor für Altersbestimmung und Isotopenforschung, Christian-Albrechts-Universität zu Kiel, 24118 Kiel, Germany \\ ${ }^{\mathrm{b}}$ National Isotope Centre, Institute of Geological and Nuclear Sciences, Lower Hutt, New Zealand \\ c Max-Planck-Institut für Biogeochemie, 07745 Jena, Germany
}

\begin{abstract}
Accelerator mass spectrometry (AMS) radiocarbon measurements were used to investigate the heterogeneity of organic matter in soils of agricultural long-term trial sites in Germany and Great Britain. The strong age heterogeneity of the soil organic matter (SOM) is reflected by highly variable ${ }^{14} \mathrm{C}$ values of different organic components, ranging from modern (>100 pMC) to 7\% modern carbon (pMC). At the field experiment in Halle (Germany), located in a heavily industrialized area, an increase of ${ }^{14} \mathrm{C}$ content with increasing depth was observed even though the input of modern plant debris should be highest in the topsoil. This is attributed to a significant contribution of old carbon (of up to $50 \%$ in the topsoil) to SOM. As a test to exclude the old carbon contamination, more specific SOM fractions were extracted. However, even a phospholipid fraction representing viable microbial biomass that is supposed to be short-lived in SOM, shows a strong influence of old, refractory carbon, when radiocarbon dated. In contrast, ${ }^{14} \mathrm{C}$ data of other field trials distant from industrial areas indicate that there inputs of old carbon to the soil are lower or even absent. Such locations are more favorable to study SOM stabilization and to quantify turnover of organic carbon in soils.
\end{abstract}

(C) 2004 Elsevier B.V. All rights reserved.

PACS: 92.70.Er; 89.60.+x

Keywords: Soil organic matter; Soil carbon stabilization; Radiocarbon; AMS

\section{Introduction}

Soils are of great importance to the global carbon cycle due to their potential to act as sinks and sources of atmospheric carbon. However, the different processes of soil carbon turnover are still

\footnotetext{
${ }^{*}$ Corresponding author. Tel.: +49-431-880-7385; fax: +49431-880-7401.

E-mail address: jrethemeyer@leibniz.uni-kiel.de (J. Rethemeyer).
}

incompletely understood, which makes it difficult to quantify sequestration of carbon in the soil system.

To improve the knowledge of carbon stabilization in soils, AMS radiocarbon measurements can be used to determine the ${ }^{14} \mathrm{C}$ content, and thus the apparent age, of bulk soil and fractionated SOM. As experimental sites the long-term agricultural field trials, of the University of Halle (Germany), the agricultural school at Rotthalmünster, and Rothamsted Experimental Station (UK) were chosen. These provide the advantage of almost 
constant and well documented conditions over many decades including cultivation in monoculture.

SOM is composed of diverse organic materials in various stages of decomposition. The heterogeneity of different organic components is reflected by their highly variable radiocarbon ages. Since a bulk SOM ${ }^{14} \mathrm{C}$ analysis only represents the mean ${ }^{14} \mathrm{C}$ concentration of the soil sample, separation of the organic matter into fractions of known origin is required. In previous studies, SOM was separated into various fractions by physical and chemical fractionation procedures and subsequently ${ }^{14} \mathrm{C}$ dated. These fractions, however, still consisted of complex mixtures of organic molecules with different origins and stabilities and ${ }^{14} \mathrm{C}$ results were therefore often difficult to interpret [1-5].

Here we present initial radiocarbon data of organic matter components and fractions obtained from surface soil as well as from a sampled depth profile at different agricultural long-term study sites, using a similar separation. Contamination of the soil at the Halle study site with old carbon severely hinders the interpretation of the ${ }^{14} \mathrm{C}$ results in terms of SOM stability.

\section{Methods}

\subsection{Study sites and soil sampling}

Soil samples were obtained from the long-term field trials in Halle, Germany. The experiment 'Eternal rye' was established in 1878 with continuous rye cropping. In 1961 another experiment with crop rotation (potatoes, oats, maize, barley, sugar beets, and wheat) was started on this experimental site. The site is located adjacent to a railway track in a highly industrialized area. The mean annual temperature in this region is $9.2{ }^{\circ} \mathrm{C}$ and the mean annual precipitation is $465 \mathrm{~mm}$. The soil type is, according to the FAO world reference base for soils [6], a Haplic Phaeozem, derived from sandy loess, consisting of $\approx 70 \%$ sand, $20 \%$ silt and $10 \%$ clay [7]. The depth of the plough horizon of both sites sampled was increased from 20 to $25 \mathrm{~cm}$ in 1970 and then to $30 \mathrm{~cm}$ in 2000 . Soil samples of the unfertilized plots on the rye culture were collected after tillage in September and December 2000. A topsoil sample $(0-25 \mathrm{~cm})$ was obtained from a soil pit. Soil samples from three different depths $(0-5,30-35,60-68 \mathrm{~cm})$ were taken by corer (6 $\mathrm{cm}$ diameter). Six replicates from the same depth were mixed to provide a representative sample of each depth. Furthermore a young rye plant, sown in September 2000, was sampled three months later. The adjacent experiment with crop rotation was sampled in March 2001 with intervals of $20 \mathrm{~cm}$ down to $60 \mathrm{~cm}$ depth, using a $2.5 \mathrm{~cm}$ diameter auger. Soil samples taken from three different locations of the unfertilized plots were mixed per depth interval.

The long-term experiment 'Broadbalk Continuous Wheat' at the Rothamsted Experimental Station, Hertfordshire, UK, was started in 1843. According to FAO, the soil has been classified as Chromic Luvisol with $\approx 21 \%$ sand, $53 \%$ silt and $26 \%$ clay $[6,8]$. Topsoil samples $(0-20 \mathrm{~cm})$ from mineral fertilized plots (P, K, Mg), taken in 1997 , were used for this study.

The topsoil $(0-20 \mathrm{~cm})$ of the agricultural trial in Rotthalmünster, Germany, established in 1979, with continuously cropped maize, was sampled in July 2002. The soil is classified as Haplic Luvisol [6] derived from loess (10\% sand, $73 \%$ silt, $17 \%$ clay).

\section{Sample treatment}

Soil samples were air dried and, as a common practice in soil science, sieved $(<2 \mathrm{~mm})$ to homogenize the material and the fraction $>2 \mathrm{~mm}$ was removed (bulk soil). Identifiable components such as plant residues and black particles were selected under the microscope and treated separately. We call the soil that was left after separating these components the 'selected soil'. Black particles of $>200 \mu \mathrm{m}$ to $2 \mathrm{~mm}$ size were separated by hand picking and cleaned with water using sonification. Inspection of these particles by light microscopy showed that this fraction is composed of different materials: shiny angular particles, porous particles, and structured particles (charred plant fragments?). 
Samples were treated with $1 \% \mathrm{HCl}$ to remove carbonates. Most samples, depending on sample size, were subsequently split into the alkali-soluble fraction (humic acid) and the residue (humin) by extraction with $1 \% \mathrm{NaOH}$ followed by $1 \% \mathrm{HCl}$ $[9,10]$. Samples were combusted at $900{ }^{\circ} \mathrm{C}$ for $4 \mathrm{~h}$ in evacuated, flame-sealed quartz tubes together with $\mathrm{CuO}$ wire and silver wool. The resulting $\mathrm{CO}_{2}$ was collected in a cold trap with liquid nitrogen and subsequently reduced to graphite with an iron catalyst and with a $10 \%$ excess of hydrogen at 600 ${ }^{\circ} \mathrm{C}[10,11]$. The precision of the AMS measurements, made at Leibniz Labor in Kiel (Germany), lies in the range of $0.3 \mathrm{pMC}$ for modern samples [11].

Lipids were extracted from fresh soil samples by shaking with chloroform, methanol, and a phosphate buffer (2.5:5:2.5 by vol). The lipid extract was applied on a column of silicic acid conditioned with chloroform and separated into neutral-, glyco-, and phospholipids by eluting with chloroform, acetone and methanol. The methanol fraction, which is mainly composed of phospholipids, is used as an indicator of microbial biomass $[12,13]$. Total lipids and phospholipids were pipetted in solution into pre-combusted quartz combustion tubes. After evaporation of the solvent, $\mathrm{CuO}$ and silver wool were added. As a precaution to avoid possible loss of highly volatile compounds the tubes were evacuated to a pressure of $\approx 10^{-4}$ mbar while immersed in dry-ice/ethanol. They were further treated as described above.

\section{Results and discussion}

Our first investigations were focused on the long-term field trial in Halle (Germany). Large variations in the radiocarbon content of different SOM fractions reflect a strong age heterogeneity at this study site. Fig. 1 shows the ${ }^{14} \mathrm{C}$ concentrations of bulk soil as well as of mechanically and chemically selected components of topsoil samples that were collected in the plough horizon at two different locations on the unfertilized plots. The ${ }^{14} \mathrm{C}$ contents of separated plant residues range from 107 to 109 pMC and are therefore in good agreement with the ${ }^{14} \mathrm{CO}_{2}$ content of the modern

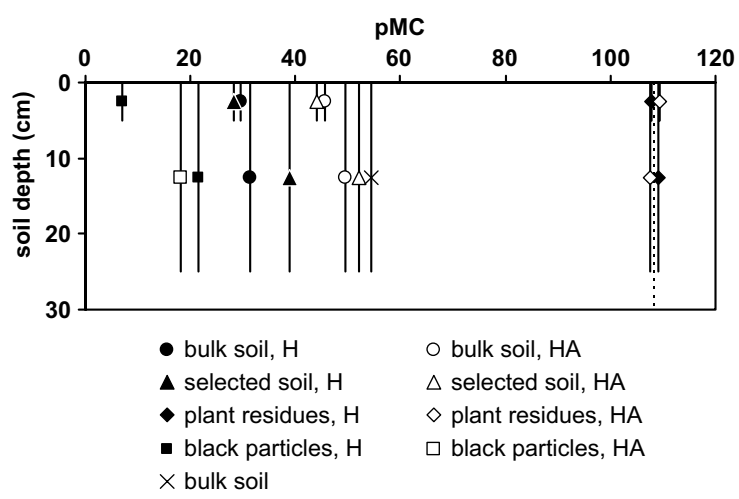

Fig. $1 .{ }^{14} \mathrm{C}$ contents of bulk and selected soil, and separated organic matter components from two topsoil samples of continuous rye plots at Halle. The symbols represent the mid-depth and the bars the sampling interval. Solid dots represent the humin fraction $(\mathrm{H})$ and open dots the humic acids (HA). The vertical, dashed line reflects the modern atmospheric ${ }^{14} \mathrm{C}$ content.

atmosphere (Schauinsland, Germany; Kromer, personal communication, 2000). A ${ }^{14} \mathrm{C}$ value of 106 pMC was measured for a young rye plant sampled in December 2000. These results show that a local 'Suess'-effect, due to a higher concentration of fossil-fuel derived $\mathrm{CO}_{2}$ in the atmosphere during winter, is only of minor importance at Halle. All other samples show a surprisingly low ${ }^{14} \mathrm{C}$ content for the near-surface SOM. The contribution of old, ${ }^{14} \mathrm{C}$-free carbon to the total SOM of the sampled plough horizon has to be more than $50 \%$ to explain the observed values. The humic acid fractions extracted from bulk and selected soils have higher ${ }^{14} \mathrm{C}$ contents than the residues of the alkali extraction (humin). The humic acids and the humin of the bulk soil both show a lower ${ }^{14} \mathrm{C}$ content than the untreated bulk soil. This apparent inconsistency indicates that the acid soluble fulvic acid fraction of SOM, which was not recovered in our procedure, must have a ${ }^{14} \mathrm{C}$ content higher than the bulk soil. Lower ${ }^{14} \mathrm{C}$ contents of bulk and selected soil samples from $0-5 \mathrm{~cm}$ compared to $0-25 \mathrm{~cm}$ sampling depth can be seen as the result of the different sampling intervals as well as of the different time of soil collection. The latter samples were obtained directly after tillage, in September 2000 and apparent ${ }^{14} \mathrm{C}$ ages are influenced by the input of recent rye straw that may be partly 
decomposed three months later, in the $0-25 \mathrm{~cm}$ samples. ${ }^{14} \mathrm{C}$ concentrations of the black particles isolated from the plough horizon range from $\approx 21.5 \mathrm{pMC}(12,350$ years $\mathrm{BP})$ to $7 \mathrm{pMC}(21,360$ years BP). This reflects the heterogeneous composition of this material containing an even larger portion of old carbon, than the soil humic acid and humin fraction.

We also studied the change of SOM ${ }^{14} \mathrm{C}$ concentrations with increasing soil depth in samples from plots with continuous rye and with crop rotation at the Halle site (Fig. 2). In general, radiocarbon ages of bulk $\mathrm{SOM}$ are expected to increase with soil depth, since in deeper soil layers the input of fresh organic material, reflecting modern atmospheric ${ }^{14} \mathrm{C}$ concentrations, and the influence of bomb ${ }^{14} \mathrm{C}$ are limited. Moreover, the stability of the organic matter should increase in deeper parts of the soil and the ${ }^{14} \mathrm{C}$ concentrations should be more strongly influenced by older carbon $[2,14,15]$. However, at Halle, located in a heavily industrialized area, we observe decreasing ${ }^{14} \mathrm{C}$ ages with increasing depth for the humic acid as well as the humin fraction of bulk and selected soil and of black particles. Again the black particles show significantly lower ${ }^{14} \mathrm{C}$ concentrations. The relatively high ${ }^{14} \mathrm{C}$ ages of the bulk soil (4880 years BP) and other SOM fractions at $0-25 \mathrm{~cm}$ depth are most probably due to a substantial input of black particles that could not be eliminated by hand picking or density fractionation. The higher ${ }^{14} \mathrm{C}$ content of most of the humic acid fractions may reflect that compounds derived from the black particles contribute less to the humic acid fraction. The very similar radiocarbon values of both humic acid and humin of bulk and selected soil in $60-68 \mathrm{~cm}$ can be explained by incomplete removal of black particles which by this depth were very small. Particle size is a practical limit for the mechanical separation of SOM components (Fig. 2).

The trial with crop rotation in Halle yields higher ${ }^{14} \mathrm{C}$ values in $0-20 \mathrm{~cm}$ depth, presumably as a consequence of a higher input of straw that is ploughed in, whereas in the monoculture experiment the rye straw was removed from the field before ploughing. In deeper parts of the soil profile the ${ }^{14} \mathrm{C}$ concentration approaches that of the rye
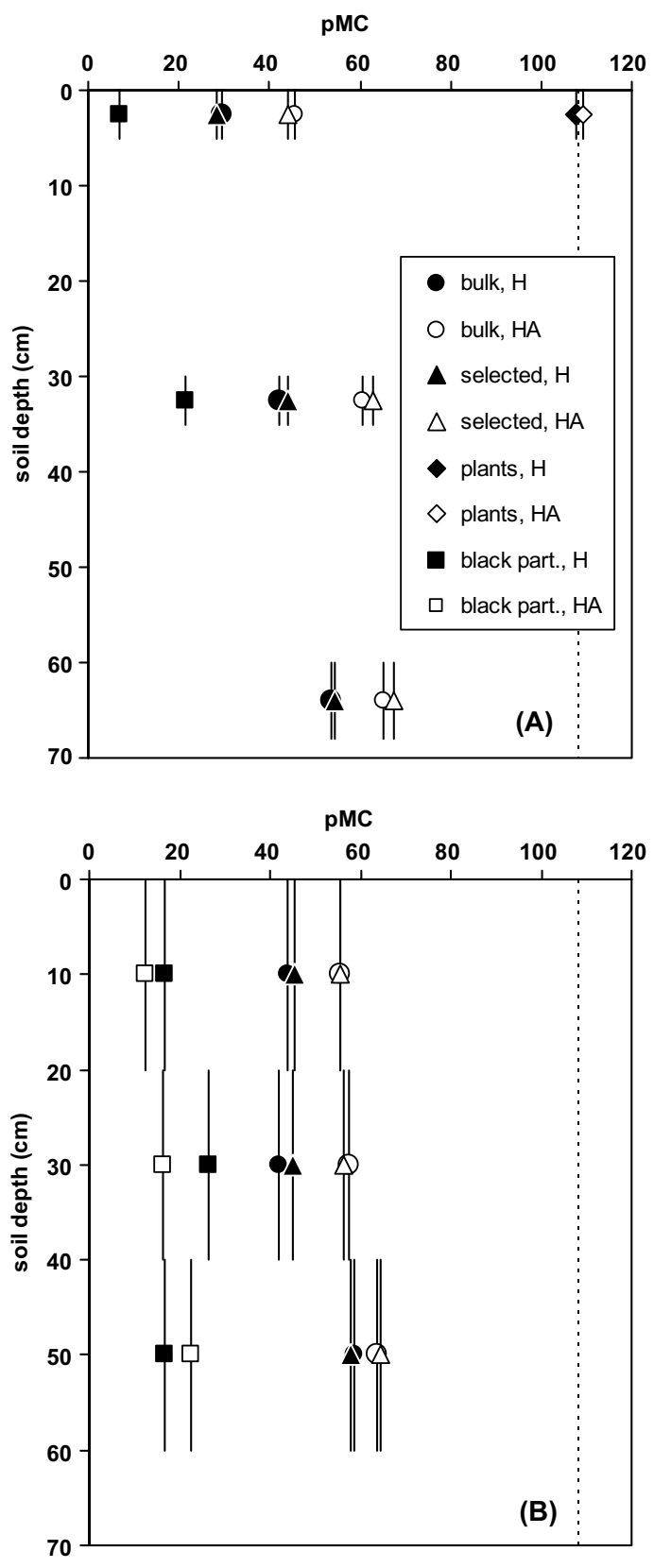

Fig. $2 .{ }^{14} \mathrm{C}$ contents of bulk and selected soil, plant residues and black particles fractionated into humin $(\mathrm{H})$ and humic acid (HA). Samples are taken in soil profiles from plots with (A) rye monoculture, and (B) crop rotation at the Halle site (Germany). The sampling interval is represented by the bar length. The measurement uncertainty $(1 \sigma)$ is within the size of the dots. The ${ }^{14} \mathrm{C}$ content of the modern atmosphere is represented by the dashed line. 
culture and contents, comparable to the results on the rye culture, are observed.

The data obtained in Halle demonstrate a variable admixture of old refractory carbon to the SOM. This complicates the quantification of carbon transformation and stabilization by radiocarbon measurements of bulk SOM and non-specific, operationally defined physical and chemical fractions. The ${ }^{14} \mathrm{C}$ concentrations, summarized in Figs. 1 and 2, indicate a heavy contamination of the SOM with old carbon at the Halle sites. Possible sources of this carbon are fly ash, emitted by surrounding industries and power plants fueled by lignite $[7,16]$, and incomplete combustion of fossil fuel by traffic. A further potential source is a nearby lignite mine (Bitterfeld/Beuna, Germany) from which airborne lignite fragments may derive. Additionally, lignite was transported also during the 1990s, on the railway line that runs parallel to the field [17]. A quantification of the contribution of different sources of old carbon to SOM, such as lignite or oil, awaits further studies, e.g. Wiesenberg et al. using molecular indicators like PAHs, hopanes, alkanes. The lower ${ }^{14} \mathrm{C}$ concentrations towards the surface of the soil profiles (Fig. 2) then reflect the increase in industrial activity and lignite use.

As an approach to overcome this contamination problem, we have isolated more specific organic fractions, which should be less influenced by old carbon. The extraction of total lipids from fresh surface soil and subsequent isolation of a fraction that mainly contains phospholipids was intended, to derive ${ }^{14} \mathrm{C}$ information for compounds that can be attributed to a specific source. Phospholipids are assumed to be indicators of microbial biomass in soils, as they are essential membrane components of living cells and short-lived in the soil $[12,18]$. At the Halle site, total lipids, extracted from fresh topsoil samples under rye monoculture, have a ${ }^{14} \mathrm{C}$ value of $42.1 \mathrm{pMC}$, which is even lower than the ${ }^{14} \mathrm{C}$ content of bulk soil (54.5 pMC). The radiocarbon content of the phospholipid fraction, isolated from total lipids by chromotrography using silicic acid columns, is higher (53.1 pMC) than the total lipid fraction and close to that of the bulk soil. The apparent high age of the phospholipid fraction (53.1 pMC, 5091 years BP) is inconsistent with the alleged lability and consequent modern origin of this compound class and suggests that most probably old carbon is incorporated in the soil microbial biomass. Similar observations were reported by Petsch et al. [19] and Rumpel et al. [20]. Recent isolation of individual phospholipid fatty acids (unpublished data) shows, however, a distinct but significantly smaller old carbon contribution. This indicates that part of the old carbon in our phospholipid fraction is present in non-phospholipids resulting from incomplete chemical separation $[21,22]$. This ability of soil microorganisms to use old and supposedly refractory material as carbon sources complicates the use of ${ }^{14} \mathrm{C}$ as a tracer if fossil carbon is present. It also questions the concept of a pool of refractory organic compounds that are biologically inert [23].

In search of a site that is less contaminated by old carbon and therefore more suitable for the study of SOM dynamics, we tested surface soil samples from agricultural field trials at the Rothamsted Experimental Station (UK) and at Rotthalmünster (Germany). ${ }^{14} \mathrm{C}$ contents in soil fractions of "Broadbalk, Continuous Wheat" (Rothamsted) show a range from 106 pMC (soil humic acid) to $88.6 \mathrm{pMC}$ (soil humin) indicating an admixture of old material that is relatively low compared to Halle (Fig. 3). The field trial in Rotthalmünster, located far from industrial areas, is probably little affected by material derived from fossil fuel because radiocarbon values for bulk soil (107.6 pMC) and the humin fraction of the selected soil (106 pMC), containing no plant residues, are close to the modern atmospheric ${ }^{14} \mathrm{C}$ content.

The admixture of old carbon ( $\mathrm{X}$ in \%) at the three sites can be estimated from the measured ${ }^{14} \mathrm{C}$ content of bulk SOM $\left(\mathrm{A}_{\text {measured }}\right)$ and the ${ }^{14} \mathrm{C}$ concentration of recent plant material $\left(\mathrm{A}_{\text {recent }}\right)$ by a simple mass balance calculation:

$\mathrm{X}=\left[1-\left(\mathrm{A}_{\text {measured }} / \mathrm{A}_{\text {recent }}\right)\right] \times 100$

By using the atmospheric ${ }^{14} \mathrm{C}$ concentration of the year of soil sampling for $\mathrm{A}_{\text {recent }}$, and assuming that recent $\mathrm{SOM}$ components are fresh plant debris, we calculated for the Halle site a contribution of old carbon to the organic matter in the topsoil of about $50 \%$. The results for Rothamsted 


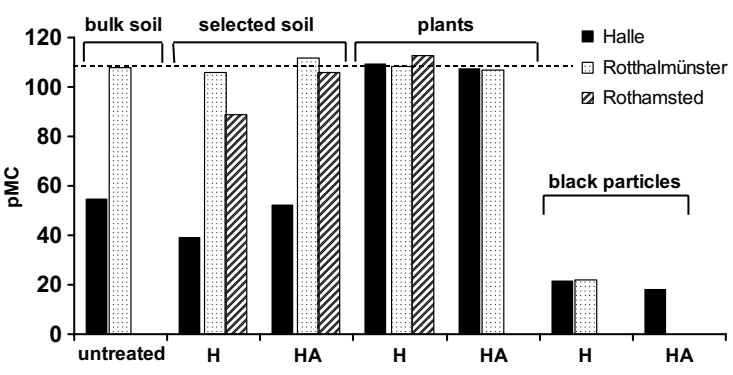

Fig. 3. Comparison of SOM ${ }^{14} \mathrm{C}$ contents of different agricultural long-term field experiments. Selected soil samples, plant residues and black particles are chemically fractionated in hu$\min (\mathrm{H})$ and humic acids (HA). The dashed line represents the modern atmospheric ${ }^{14} \mathrm{C}$ concentration.

indicate a contribution of $\approx 19.5 \%$ old material in the soil humin fraction. Only $2.2 \% \mathrm{C}$ derived from old carbon was calculated for the humin fraction at Rotthalmünster. The calculations above are approximate because: (1) in reality recent SOM will be a mixture of plant residues and decomposition products from several years, with decreasing contributions from older years, (2) the large changes in atmospheric ${ }^{14} \mathrm{C}$ concentration due to aboveground nuclear weapons testing resulted in strongly variable ${ }^{14} \mathrm{C}$ contents in modern vegetation $\left(\mathrm{A}_{\text {recent }}\right)$, and (3) additional mixing is caused by soil tillage and changes in plough depth. More sophisticated results can be obtained by calculating a weighted mean ${ }^{14} \mathrm{C}$ content of recent SOM by various decomposition models.

\section{Conclusion}

Radiocarbon measurements of bulk soil and SOM fractions reflect the mixture of young and old organic material in soils. Since fossil fuel related, ${ }^{14} \mathrm{C}$-free organic carbon in soils can strongly influence the composition and dynamics of the soil carbon reservoir, ${ }^{14} \mathrm{C}$ measurements are helpful by detecting and quantifying this old fraction. The admixture of old carbon to SOM of the experimental site at Halle, located in a heavily industrial area, is very high (up to $50 \%$ in the topsoil). Nonspecific physical and chemical fractionation of the organic material does not exclude the old contamination. However, even more specific SOM fractions, such as phospholipids, yielded unexpectedly low ${ }^{14} \mathrm{C}$ contents, and must be assumed to reflect an incorporation of old carbon by soil microorganisms. Our results indicate that an old carbon fraction is less important at Rothamsted and may be negligible at Rotthalmünster. To study the stabilization of organic carbon in soil further investigations on less contaminated sites are required.

\section{Acknowledgements}

This project is funded by the German Science Foundation (DFG) within the Priority Program 1090 "Soils as source and sink for $\mathrm{CO}_{2}-$ mechanisms and regulation of organic matter stabilization in soils". We thank the members of the Leibniz-Labor for their helpful assistance at sample processing and AMS analysis and our colleagues in the DFG-Priority Program for cooperations and helpful discussions.

\section{References}

[1] S.E. Trumbore, J.S. Vogel, J.R. Southon, Radiocarbon 31 (1989) 644.

[2] H.W. Scharpenseel, P. Becker-Heidmann, H.U. Neue, K. Tsutsuki, Sci. Total Environ. 81/82 (1989) 99.

[3] H.W. Scharpenseel, P. Becker-Heidmann, Radiocarbon 34 (1992) 541.

[4] J.O. Skjemstad, P. Clark, J.A. Taylor, J.M. Oades, S.G. McClure, Aust. J. Soil Res. 34 (1996) 251.

[5] S.E. Trumbore, G. Bonani, W. Wölfli, in: A.F. Bouwman (Ed.), Soils and the Greenhause Effect, John Wiley, New York, 1990, p. 405.

[6] FAO-ISRIC, Guidelines for soil description, third ed. revised, Food and Agricultural Organisation, Rome, 1990.

[7] W. Merbach, L. Schmidt, L. Wittemayer (Eds.), Teubner, Stuttgart/Leipzig, 1999.

[8] D.S. Jenkinson, D.D. Harkness, E.D. Vance, D.E. Adams, A.F. Harrison, Soil Biol. Biochem. 24 (1992) 295.

[9] J.S. Vogel, J.R. Southon, D.E. Nelson, T.A. Brown, Nucl. Instr. and Meth. B 5 (1984) 289.

[10] M.J. Nadeau, M. Schleicher, P.M. Grootes, H. Erlenkeuser, A. Gottdang, D.J.W. Mous, J.M. Sarnthein, H. Willkomm, Nucl. Instr. and Meth. B 123 (1997) 22.

[11] M.J. Nadeau, P.M. Grootes, M. Schleicher, P. Hasselberg, A. Rieck, M. Bitterling, Radiocarbon 40 (1998) 239.

[12] L. Zelles, Biol. Fertil. Soils 29 (1999) 111. 
[13] Å. Frostegård, A. Tunlid, E. Bååth, Appl. Environ. Microbiol. (1993) 3605.

[14] K.G. Harrison, Radiocarbon 38 (1996) 181.

[15] P.F.A.M. Römkens, J. Hassink, J. van der Plicht, Radiocarbon 40 (1998) 1023.

[16] M. Enders, H.U. Bambauer, Euro. J. Mineral. 6 (1994) 60.

[17] G.L.B. Wiesenberg, J. Schwarzbauer, M.W.I. Schmidt, L. Schwark, Org. Geochem., in press.

[18] D.A. Bossio, K.M. Scow, Microb. Ecol. 35 (1998) 265.
[19] S.T. Petsch, T.I. Eglinton, K.J. Edwards, Science 292 (2001) 1127.

[20] C. Rumpel, P.M. Grootes, I. Kögel-Knabner, Org. Geochem. 33 (2001) 2019.

[21] E. Aries, P. Doumenq, J. Artaud, J. Molinet, J.C. Bertrand, Org. Geochem. 32 (2001) 193.

[22] P. Nielsen, S.O. Petersen, Soil Biol. Biochem. 32 (2000) 1241.

[23] P. Falloon, P. Smith, K. Coleman, S. Marshall, Soil Biol. Biochem. 32 (2000) 433. 